\title{
A Burmese amber fossil of Radula (Porellales, Jungermanniopsida) provides insights into the Cretaceous evolution of epiphytic lineages of leafy liverworts
}

\author{
Julia Bechteler ${ }^{1}$, Alexander R. Schmidt ${ }^{2}$, Matthew A. M. Renner ${ }^{3}$, Bo Wang ${ }^{4}$, Oscar Alejandro Pérez-Escobar ${ }^{1,5}$, \\ Alfons Schäfer-Verwimp ${ }^{6}$, Kathrin Feldberg ${ }^{1}$, and Jochen Heinrichs ${ }^{1}$ \\ ${ }^{1}$ Department of Biology and GeoBio-Center, Ludwig Maximilian University, Menzinger Straße 67, 80638 Munich, Germany \\ ${ }^{2}$ Department of Geobiology, Georg August University, Goldschmidtstraße 3, 37077 Göttingen, Germany \\ ${ }^{3}$ Royal Botanic Gardens and Domain Trust, Mrs Macquaries Road, Sydney, NSW 2000, Australia \\ ${ }^{4}$ State Key Laboratory of Palaeobiology and Stratigraphy, Nanjing Institute of Geology and Palaeontology, Chinese Academy \\ of Sciences, No.39, East Beijing Road, Nanjing 210008, China \\ ${ }^{5}$ Department of Identification and Naming, Royal Botanic Gardens Kew, Richmond, TW9 3AB, UK \\ ${ }^{6}$ Mittlere Letten 11, 88634 Herdwangen-Schönach, Germany
}

Correspondence to: Jochen Heinrichs (jheinrichs@1mu.de)

Received: 24 May 2017 - Revised: 21 June 2017 - Accepted: 23 June 2017 - Published: 27 July 2017

\begin{abstract}
DNA-based divergence time estimates suggested major changes in the composition of epiphyte lineages of liverworts during the Cretaceous; however, evidence from the fossil record is scarce. We present the first Cretaceous fossil of the predominantly epiphytic leafy liverwort genus Radula in ca. $100 \mathrm{Myr}$ old Burmese amber. The fossil's exquisite preservation allows first insights into the morphology of early crown group representatives of Radula occurring in gymnosperm-dominated forests. Ancestral character state reconstruction aligns the fossil with the crown group of Radula subg. Odontoradula; however, corresponding divergence time estimates using the software BEAST lead to unrealistically old age estimates. Alternatively, assignment of the fossil to the stem of subg. Odontoradula results in a stem age estimate of Radula of $227.8 \mathrm{Ma}$ (95\% highest posterior density (HPD): 165.7-306.7) and a crown group estimate of $176.3 \mathrm{Ma}$ (135.1-227.4), in agreement with analyses employing standard substitution rates (stem age $235.6 \mathrm{Ma}$ (142.9-368.5), crown group age $183.8 \mathrm{Ma}$ (109.9-289.1)). The fossil likely belongs to the stem lineage of Radula subg. Odontoradula. The fossil's modern morphology suggests that switches from gymnosperm to angiosperm phorophytes occurred without changes in plant body plans in epiphytic liverworts. The fossil provides evidence for striking morphological homoplasy in time. Even conservative node
\end{abstract}

assignments of the fossil support older rather than younger age estimates of the Radula crown group, involving origins for most extant subgenera by the end of the Cretaceous and diversification of their crown groups in the Cenozoic.

\section{Introduction}

DNA-based divergence time estimates suggest major changes in the composition of epiphyte lineages of liverworts, mosses, and ferns during the Cretaceous radiation of main angiosperm lineages (Schuettpelz and Pryer, 2006; Newton et al., 2007; Hennequin et al., 2008; Cooper et al., 2012; Feldberg et al., 2014). These lineages may have benefitted from the more humid climate of angiosperm-dominated forests compared to gymnosperm forests (Boyce et al., 2010; Boyce et al., 2010; Boyce and Leslie, 2012; Zwieniecki and Boyce, 2014); however, evidence from the fossil record is scarce (Taylor et al., 2009). Only very few well-preserved Cretaceous fossils of leafy liverworts have been observed, of which some have been placed in the extant genera Frullania Raddi (Heinrichs et al., 2012) and Gackstroemia Trevis. (Heinrichs et al., 2014), whereas others have been assigned to fossil genera with somewhat unclear relationships (Kaolakia Heinrichs, M. E. Reiner, Feldberg, von Konrat \& 
A. R. Schmidt, Heinrichs et al., 2011; Diettertia J. T. Br. \& Robison, Schuster and Janssens, 1989). Cretaceous fossils of thallose liverworts are more numerous but generally poorly preserved (Fletcher et al., 2008; Li et al., 2014, 2016; Tomescu, 2016) and can hardly be aligned with extant genera or families (Laenen et al., 2014; Villarreal et al., 2016). Considering the importance of the Cretaceous for the evolution of epiphytic lineages of liverworts (Feldberg et al., 2014) and our scarce knowledge on the morphology of these plants, an extension of the Cretaceous fossil record of liverworts is very desirable.

With some 250 species (Yamada, 1986; Söderström et al., 2016), Radula Dumort. is one of the largest genera of the Porellales, a predominantly epiphytic clade of leafy liverworts (Heinrichs et al., 2005). Radula is well known for its rather monotonous, reduced morphology, for example in the absence of underleaves and the rather uniformly shaped, predominantly entire-margined leaves. It has been included in several integrative taxonomic studies that identified numerous inconsistencies in previous morphology-based classifications and molecular topologies (Devos et al., 2011b; Renner et al., 2013c, 2014; Renner, 2014). These studies led to new hypotheses on species ranges and species circumscriptions (Patiño et al., 2013, 2017; Renner et al., 2013a) and a new supraspecific classification (Devos et al., 2011b). Most importantly, these studies demonstrated the presence of morphologically very similar plants in different main lineages, and morphological convergence caused by lineages repeatedly traversing shared regions of morphospace appeared commonplace (Renner, 2015). As a consequence, many Radula species cannot be assigned with confidence to the recently established subgenera using morphological evidence alone (Devos et al., 2011b).

Until now, five fossil species of Radula were known, all from the Cenozoic. These include the Eocene-Oligocene Bitterfeld or Baltic amber fossils $R$. baltica Heinrichs, Schäf.-Verw. \& M. A. M. Renner; R. oblongifolia Casp.; and R. sphaerocarpoides Grolle (Heinrichs et al., 2016b) and the Miocene Dominican amber fossils R. steerei Grolle (Grolle, 1987 ) and $R$. intecta M. A. M. Renner, Schäf.-Verw. \& Heinrichs (Kaasalainen et al., 2017). The subgeneric affiliation of these fossils is unclear and, accordingly, they were not assigned to any crown group node of Radula in divergence time estimates based on DNA sequence data of extant species (Patiño et al., 2017). These studies relied on standard substitution rates of chloroplast DNA of seed-free land plants (Palmer, 1991; Villarreal and Renner, 2014) and suggested a Jurassic origin of Radula and divergence of the extant subgenera in the Cretaceous (Patiño et al., 2017).

Here, we present a well-preserved fossil of Radula in ca. 100 Myr old Burmese amber from Myanmar, which extends by some $65 \mathrm{Myr}$ the temporal range encompassed by Radula fossils. We reconstruct the character states of the fossil on a comprehensive phylogeny of Radula and discuss the possible relationships of the fossil to extant subgenera. We present a series of divergence time estimates to consider possible crown and stem group assignments and examine the fossils' importance for understanding the evolutionary history of Radula.

\section{Material and methods}

\subsection{Amber fossil}

Burmese amber derives from the amber localities near the village of Tanai in Kachin State, Myanmar (Grimaldi et al., 2002; Kania et al., 2015). Biostratigraphic studies (Cruickshank and Ko, 2003) and U-Pb dating of zircons (Shi et al., 2012) revealed a late Albian to earliest Cenomanian age of Burmese amber, with a minimum age of $98 \mathrm{Ma}$. The amber inclusion was examined under a Carl Zeiss Stereo Discovery V8 dissection microscope and a Carl Zeiss Axio Scope A1 compound microscope using incident and transmitted light simultaneously. Images were taken with Canon EOS 5D digital cameras attached to the microscopes. For enhanced illustration of three-dimensional structures, all figures are photomicrographic composites that were digitally stacked from up to 43 focal planes, using the software package Helicon Focus 6.7 (Fig. 1).

\subsection{Phylogenetic analyses}

A molecular dataset for Radula species was compiled based on GenBank sequences used in previous studies by Devos et al. (2011a) and Patiño et al. (2017). Plastid $\operatorname{trn} \mathrm{L}-\mathrm{F}, \operatorname{trn} \mathrm{G}$, $a t p \mathrm{~B}, p s b \mathrm{~T}, r p s 4$, and $p s b \mathrm{~A}$ sequences of 99 Radula accessions were downloaded from GenBank, and sequences of $R$. pugioniformis M. A. M. Renner were newly generated for this study following the protocol given in Devos et al. (2011a, b). Lepidolaena clavigera Hook., Dumort. ex Trevis.; Porella navicularis (Lehm. \& Lindenb.) Pfeiff.; Lejeunea tuberculosa Steph.; and Frullania sp. served as outgroup taxa. Herbarium voucher numbers and their GenBank accession numbers are given in the Supplement. Sequences were manually aligned in Geneious version 6 (Kearse et al., 2012). The Akaike information criterion (AIC; Akaike, 1973) in jModelTest 2 (Darriba et al., 2012) was employed to select the best-fit models of evolution for each of the six plastid markers. This resulted in a TIM1+I+G model for $\operatorname{trn} \mathrm{L}-\mathrm{F}$; a $\mathrm{TVM}+\mathrm{G}$ model for $t r n \mathrm{G}$; a $\mathrm{TVM}+\mathrm{I}+\mathrm{G}$ model for $a t p \mathrm{~B}$, $p s b \mathrm{~T}$, and $r p s 4$; and a GTR $+\mathrm{I}+\mathrm{G}$ model for $p s b \mathrm{~A}$ and the concatenated six-marker dataset.

\subsection{Phylogeny reconstruction}

An ultrametric starting tree was generated in BEAST 1.8.2 for further analyses (Drummond et al., 2012) by using an uncorrelated log-normal (UCLN) relaxed clock model and a birth-death prior accounting for incomplete sampling (Stadler, 2009), running the analysis for 40 million gen- 

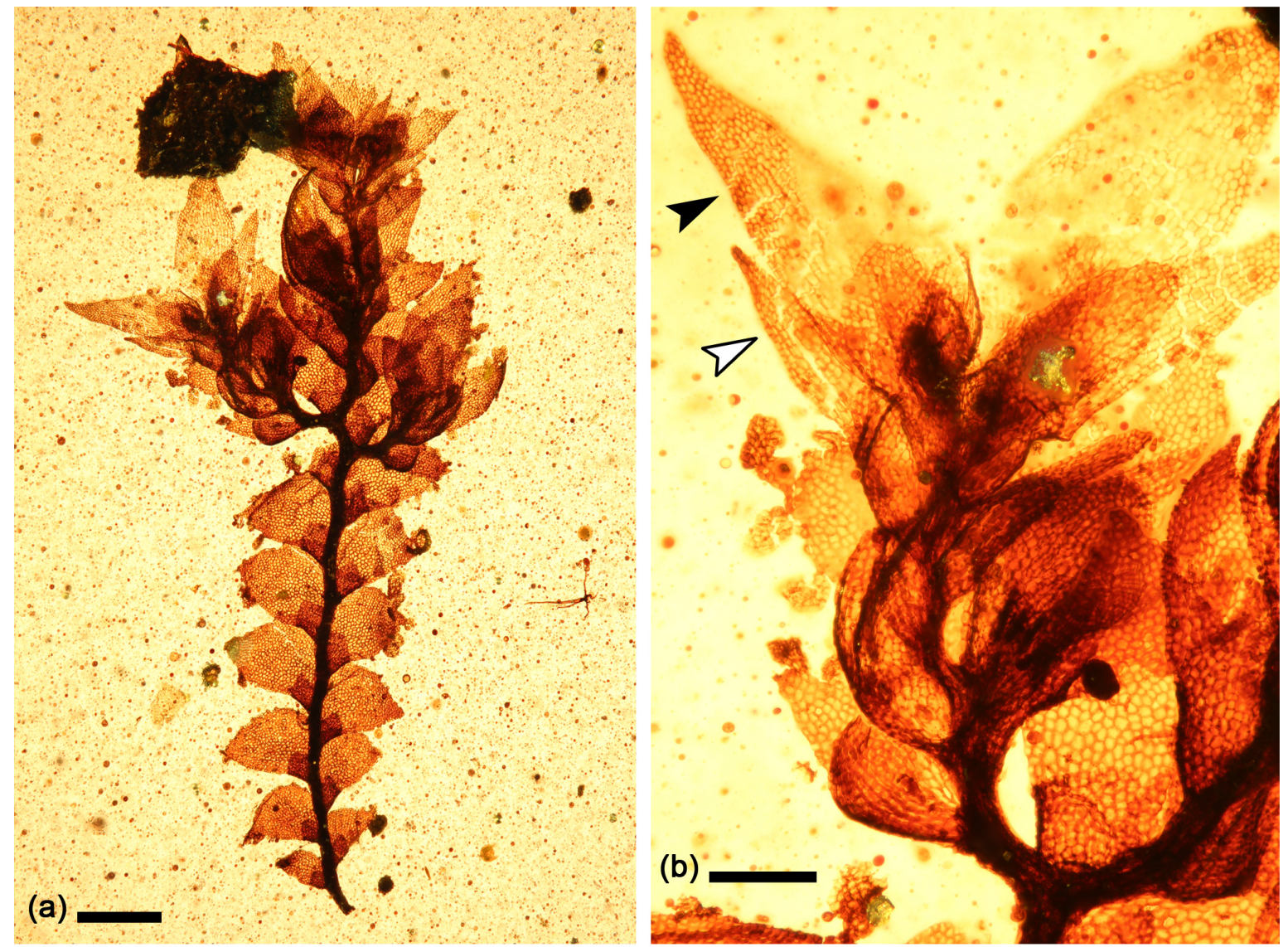

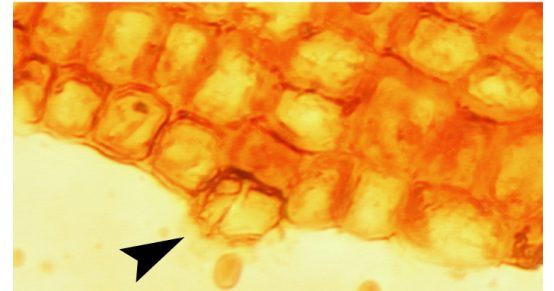

(c)

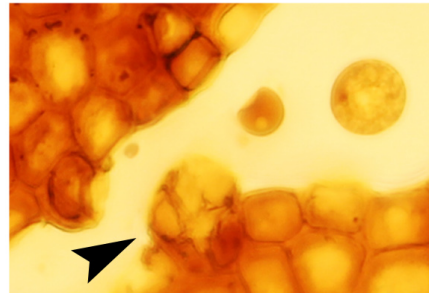

(d)

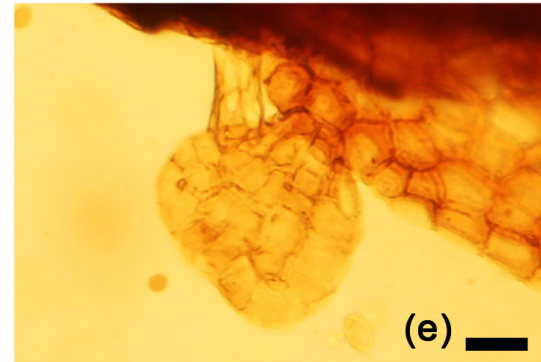

(e)
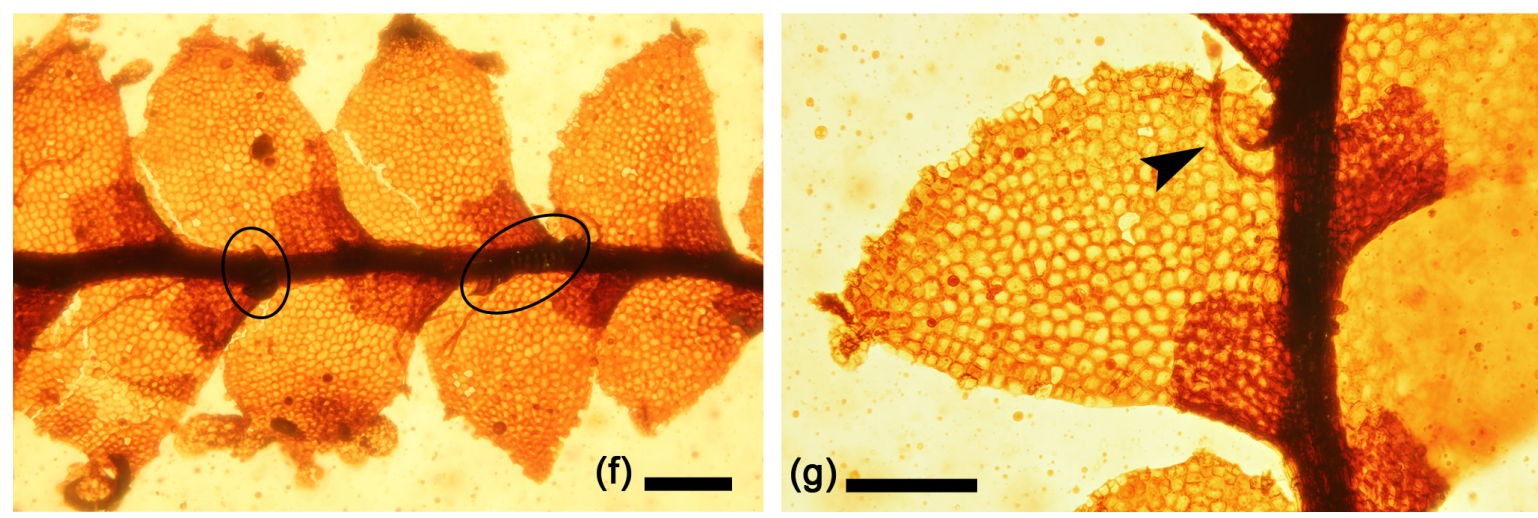

Figure 1. Radula cretacea sp. nov. from Cretaceous Burmese amber (PB22484). (a) Overview of the fossil. (b) Upper portion of shoot with female bract pairs. The white arrowhead points to the outer bract; the black arrowhead points to the inner female bract. (c-e) Gemmae in different developmental stages. (f) Portion of the shoot. Two fern sporangia (encircled) are attached to the stem of the Radula fossil. (g) Leaf. Note the acute leaf apex and gemmae development at its margin. The arrowhead points to a degraded fern sporangium. Scale bars: (a) $500 \mu \mathrm{m}$, (b, f) $200 \mu \mathrm{m},(\mathbf{g}) 150 \mu \mathrm{m}$, and (c, d, e) $20 \mu \mathrm{m}$. (a-e, g) Fossil in ventral view and (f) in dorsal view. 
erations and sampling every 4000 generations. A single GTR $+\mathrm{I}+\mathrm{G}$ model as suggested by jModelTest 2 was employed for the concatenated dataset in all analyses. The quality of the run was assessed in TRACER (Rambaut et al., 2014) in which effective sample size (ESS) values $>200$ indicated good mixing and a sufficient number of generations. The resulting maximum clade credibility (MCC) tree was generated in TreeAnnotator 1.8.2 (Drummond et al., 2012) using median node heights, excluding the first $10 \%$ of trees as burn-in. The tree was visualized using FigTree (http://tree.bio.ed.ac.uk/software/figtree/).

\subsection{Ancestral character state reconstruction}

Four characters possessed by the fossil are potentially informative regarding the fossil's phylogenetic relationships. These characters are the acute to acuminate leaf lobe apex, the two pairs of female bracts, the longitudinal lobule insertion, and the production of gemmae from the leaf-lobe margin. Other potentially informative character systems such as perianth structure, sporophyte anatomy, and spores are not preserved in the fossil. Ancestral character states were estimated on the MCC topology after reducing the outgroup taxa to Porella navicularis. A maximum likelihood approach implemented in the ape package v3.5 (Paradis et al., 2004) in R v3.3.0 (R Core Team, 2016) was employed to infer the evolution of the following discrete morphological characters for Radula: presence and absence of gemmae, number of female bract pairs, shape of the lobule insertion (transverse, longitudinal), and shape of the leaf apex (round, acute). The coding matrices can be found in the Supplement. Two models, parameterizing the transition rates among the states were compared using the log likelihood values, namely an equal rates model and an all-rates-different model.

\subsection{Divergence time estimates}

Divergence time estimates were obtained using BEAST 1.8.2. The MCC tree was employed as the starting tree for all subsequent analyses, in which the ingroup was constrained monophyletic, with run lengths of 100 million generations, sampling every 10000 generations. Three different calibration approaches were conducted. In the first, a plastid standard substitution rate of $5 \times 10^{-4}$ subst./sites/Myr (Palmer, 1991; Villarreal and Renner, 2014) with a standard deviation (SD) of $1 \times 10^{-4}$, and a normal prior distribution was used. In the second, the fossil was given a crown group assignment within $R$. subgenus Odontoradula K. Yamada according to morphological similarity of the fossil with extant taxa of this group and character state reconstructions (Fig. 2). In detail, the clade consisting of Radula ocellata K. Yamada, R. pulchella Mitt., $R$. cuspidata Steph., $R$. acuta Mitt., $R$. novaehollandiae Hampe, $R$. kojana Steph., and $R$. apiculata Sande Lac. ex Steph. was set to monophyletic and the include stem option was activated. A normal prior distribution with a mean of $98.0 \mathrm{Ma}$ and a SD of 1.0 was used, corresponding to the age of the Burmese amber fossil. In the third approach, the fossil was placed on the stem of $R$. subgenus Odontoradula and the same prior information for the fossil age was used. This approach considered the distribution of the fossil's character states suggesting $R$. subgenus Odontoradula. Published divergence time estimates of Radula were gathered from the literature (Heinrichs et al., 2007; Fiz-Palacios et al., 2011; Cooper et al., 2012; Feldberg et al., 2014; Laenen et al., 2014; see Supplement) and compared with the results of the present analyses.

Stepping-stone sampling in BEAST (Xie et al., 2011; Baele et al., 2012, 2013) and the resulting log-marginal likelihood values and ln-Bayes factor (Kass and Raftery, 1995) values helped to select between pure birth (Yule), birthdeath, and birth-death incomplete sampling tree priors, as well as between the UCLN relaxed clock and a strict clock model. The model comparison was conducted using the first calibration approach, and the resulting combination of a birth-death tree prior and an UCLN relaxed clock model was assigned to the other calibration approaches. Log-marginal likelihood values and $\ln$-Bayes factor values are shown in Table 1. All results were examined in TRACER, summarized in TreeAnnotator, and visualized in FigTree as reported above.

\section{Results}

\subsection{Ancestral character state reconstruction}

The all-rates-different model was selected as the best-fit model for all four ancestral character state reconstructions (Table 2). Results are shown in Fig. 2 in which a yellow color coding refers to the character state of the Radula fossil. A round leaf apex was inferred as the ancestral state for Radula, whereas a transition to an acute leaf apex was reconstructed for the common ancestor of Radula pugioniformis M. A. M. Renner, $R$. ocellata, $R$. pulchella Mitt., $R$. cuspidata, $R$. acuta, $R$. novae-hollandiae, $R$. kojana, and $R$. apiculata. Acute leaf apices also occur in a single species of $R$. subg. Amentuloradula Devos, M. A. M. Renner, Gradst., A. J. Shaw \& Vanderp. among those included in the phylogeny. The same pattern was observed for the number of female bract pairs, which changed from one to two female bract pairs within subgenus Odontoradula. The lack of gemmae production was inferred as the ancestral state for Radula and a transition to the development of gemmae occurred independently within the subgenera Odontoradula, Volutoradula Devos, M. A. M. Renner, Gradst., A. J. Shaw $\&$ Vanderp., Radula, and Metaradula R. M. Schust. Only one transition from a transverse to a longitudinal lobule insertion was inferred at the most recent common ancestor of the subgenera Odontoradula, Amentuloradula, Radula, Metaradula, and Volutoradula. 
(a) Leaf apex

- Round

Acute

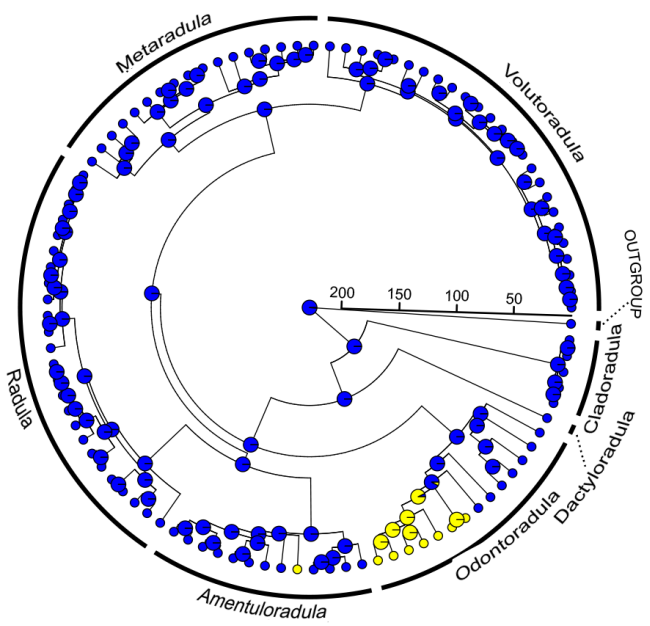

(c) Gemmae

- Absent

Present

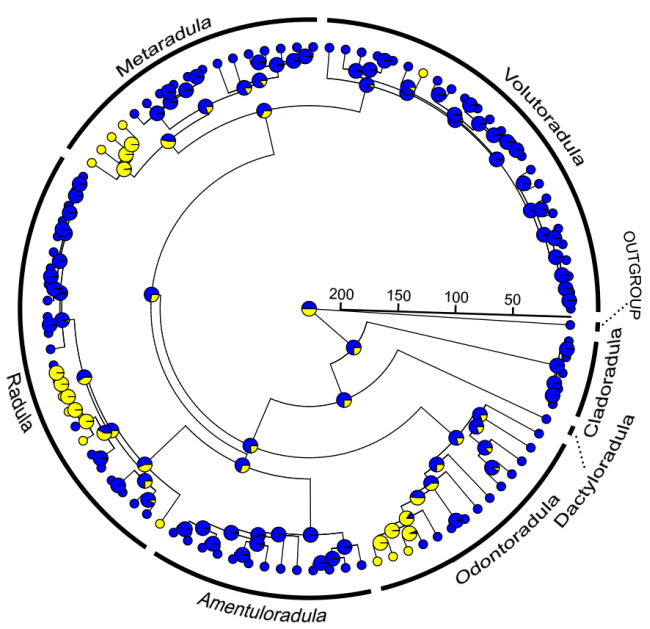

(b) Female bract pairs

- 1

○ 2

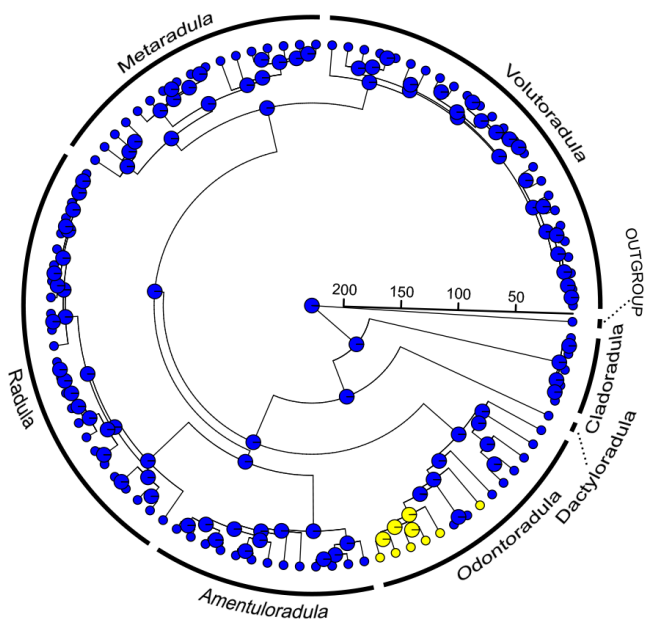

(d) Lobule insertion

- Transverse

$\bigcirc$ Longitudinal

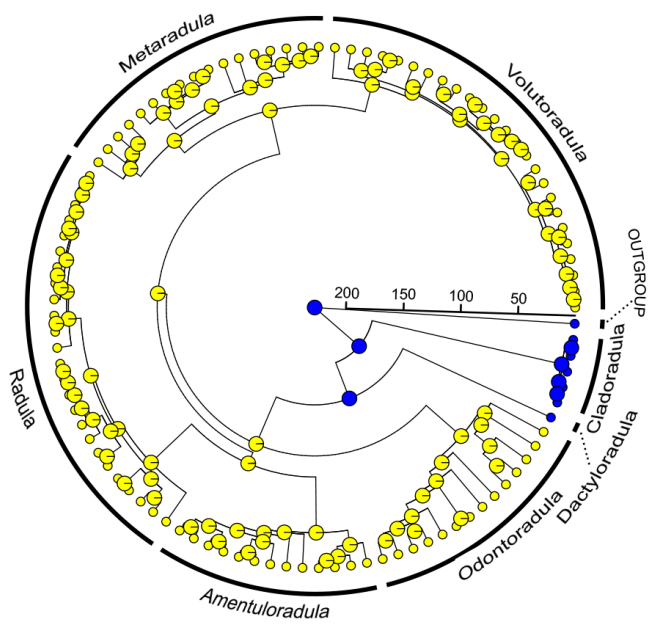

Figure 2. Results of ancestral character state reconstructions. (a) Shape of leaf apex. (b) Number of female bract pairs. (c) Gemmae development. (d) Type of lobule insertion. Yellow color coding refers to the morphological characters observed in the fossil.

Table 1. Marginal likelihood estimations using stepping-stone sampling in BEAST and ln-Bayes factor calculation resulting in an uncorrelated log-normal (UCLN) relaxed clock model. Since the birth-death (BD) tree prior and the birth-death tree prior accounting for incomplete sampling (BD incompl.) did not differ significantly, the less complex BD tree prior was used.

\begin{tabular}{lrrrrr}
\hline & Model 1 & UCLN, Yule & UCLN, BD & UCLN, BD incompl. & Strict clock, BD \\
\hline Model 2 & Log-marginal likelihood & -23875.92 & -23865.00 & -23864.05 & -23965.95 \\
UCLN, Yule & -23875.92 & 0.00 & 10.92 & 11.87 & -90.03 \\
UCLN, BD & -23865.00 & -10.92 & 0.00 & 0.95 & -100.95 \\
UCLN, BD incompl. & -23864.05 & -11.87 & -0.95 & 0.00 & -101.90 \\
Strict clock, BD & -23965.95 & 90.03 & 100.95 & 101.90 & 0.00 \\
\hline
\end{tabular}


Table 2. Results of the ancestral character state reconstruction favoring an all-rates-different model for all analyzed morphological characters.

\begin{tabular}{lrr}
\hline $\begin{array}{l}\text { Morphological } \\
\text { character }\end{array}$ & $\begin{array}{r}\text { Equal-rates } \\
\text { model (ER) } \\
\log \text { likelihood }\end{array}$ & $\begin{array}{r}\text { All-rates- } \\
\text { different model (ARD) } \\
\log \text { likelihood }\end{array}$ \\
\hline Leaf apex & -11.149 & -11.145 \\
Female bract pairs & -10.853 & -10.632 \\
Gemmae & -34.241 & -29.532 \\
Lobule insertion & -4.919 & -3.696 \\
\hline
\end{tabular}

\subsection{Molecular dating analyses}

Calibration of the dataset with the plastid standard substitution rate resulted in an estimated divergence between Radula and the outgroup ranging from Devonian to early Cretaceous (235.6 Ma, 95\% HPD: 142.9-368.5), and crown group divergences between the early Permian and early Cretaceous (183.8 Ma, 95 \% HPD: 109.9-289.1). Establishment of most extant species likely took place within the Neogene. Divergence time estimates resulting from an assignment of the fossil to the crown of subgenus Odontoradula resulted in much older age estimates. Under this crown-assignment dating strategy, the Radula stem was estimated to originate sometime from the Neoproterozoic (Cryogenian) to the early Carboniferous (508.1 Ma, 95\% HPD: 340.7-713.8) and its crown group from the late Neoproterozoic (Ediacaran) to the middle Permian (392.2 Ma, 95\% HPD: 266.5-551.5). The calibration approach placing the fossil on the stem of subgenus Odontoradula results in a stem age estimate of Radula dating back to the late Triassic (227.8 Ma, 95\% HPD: 165.7306.7) and the origin of its crown group is estimated to the early Jurassic (176.3 Ma, $95 \%$ HPD: 135.1-227.4). Since all analyses yielded the same topology, a phylogenetic chronogram with three scale axes referring to the three calibration approaches is presented as Fig. 3, while Table 3 shows the corresponding estimated divergence times and their $95 \%$ HPD intervals for selected nodes.

\subsection{Systematic palaeontology}

Radula cretacea Bechteler, M. A. M. Renner, Schäf.-Verw. \& Heinrichs, sp. nov.

Holotype: Single liverwort fossil in Burmese amber piece PB22484 of the Nanjing Institute of Geology and Palaeontology, Chinese Academy of Sciences (Fig. 1; syninclusions: composed plant hairs and degraded sporangia of leptosporangiate ferns).

Diagnosis: Species of Radula distinctive in its possession of leaves whose apex is acute to acuminate, gemmae produced from leaf-lobe marginal cells only, and female bracts in two pairs. From other species of Radula sharing these characters, the fossil differs in the production of subfloral innovations from the base of the upper pair of female bracts, in the cochleariform lobules on leaves transitional between female bracts and vegetative leaves, and the lanceolate lobes of the female bracts.

Description: Shoot $800-1160 \mu \mathrm{m}$ wide; stem $65-85 \mu \mathrm{m}$ wide and four or five cortical cell rows across. Branching Radula type. Leaves remote at shoot base, becoming contiguous then imbricate as stature increases along shoot, ovate, spreading, not obliquely patent, $270-600 \mu \mathrm{m}$ long by 200-560 $\mu \mathrm{m}$ wide, postical margin straight to slightly curved along inner half, curved toward apex along outer half, apex acute to slightly acuminate, antical margin more or less straight or weakly curved near apex, curvature increasing toward stem, interior margin curved but not ampliate, hardly extending onto the dorsal stem surface, leaving the stem visible from above. Lobules around the area of leaf lobes; quadrate to trapeziform, $90-165 \mu \mathrm{m}$ long by $110-210 \mu \mathrm{m}$ wide, insertion longitudinal; keel arising from stem at $45^{\circ}$ angle, running flush into the lobe outline, or meeting at a slight angle straight to slightly arched; exterior and antical margins straight to slightly curved, slightly irregular due to bulging marginal cells, apex obtuse to slightly attenuate, with shallow notch between two cells wherein papilla is situated (observed in one lobule); interior margin not ampliate, not extending onto ventral stem surface. Ventral leaf-free strip present, perhaps two cortical cell rows only; presence or absence of dorsal leaf-free strip not ascertained. Cells on leaf margin quadrate to rectangular, $12.5-27.5 \mu \mathrm{m}$ long by $12.5-17.5 \mu \mathrm{m}$ wide, long axis either perpendicular or parallel with leaf margin; medial cells isodiametric to slightly elongate, irregularly sized and arranged, $20-30 \mu \mathrm{m}$ long by $15-25 \mu \mathrm{m}$ wide, basal cells slightly larger, $30-35 \mu \mathrm{m}$ long by $22.5-30 \mu \mathrm{m}$ wide; cell medial walls unthickened, small concave trigones, possibly consisting entirely of primary wall material, present at cell angles, free exterior wall of marginal cells unthickened. Asexual reproduction by gemmae produced from cells of leaf margin, gemmae unistratose, subdiscoid to obcordate to thalloid as size increases, $50-185 \mu \mathrm{m}$ or more in length and $45-125 \mu \mathrm{m}$ in width. (?)Dioicous. Gynoecia terminal on leading axes and short lateral branches. Female bracts in two pairs, both larger than preceding leaves, transitional leaves bearing enlarged obovate and cochleariform lobules present between bracts and leaves; upper female bract lobe lanceolate, $990-1150 \mu \mathrm{m}$ long by $300-410 \mu \mathrm{m}$ wide, apex acuminate, medial cells $25-40 \mu \mathrm{m}$ long by $20-25 \mu \mathrm{m}$ wide, walls unthickened; upper bract lobule broad-elliptic to obovate or obtrullate, $480-570 \mu \mathrm{m}$ long by $280-340 \mu \mathrm{m}$ wide; lower female bract lobe lanceolate $620-820 \mu \mathrm{m}$ long by $190-210 \mu \mathrm{m}$ wide, apex acuminate, lobule obovate, $340-390 \mu \mathrm{m}$ long by $160-250 \mu \mathrm{m}$ wide, bracts imbricate, long axis orientated at around $30^{\circ}$ to stem. A single Radula-type subfloral innovation present 


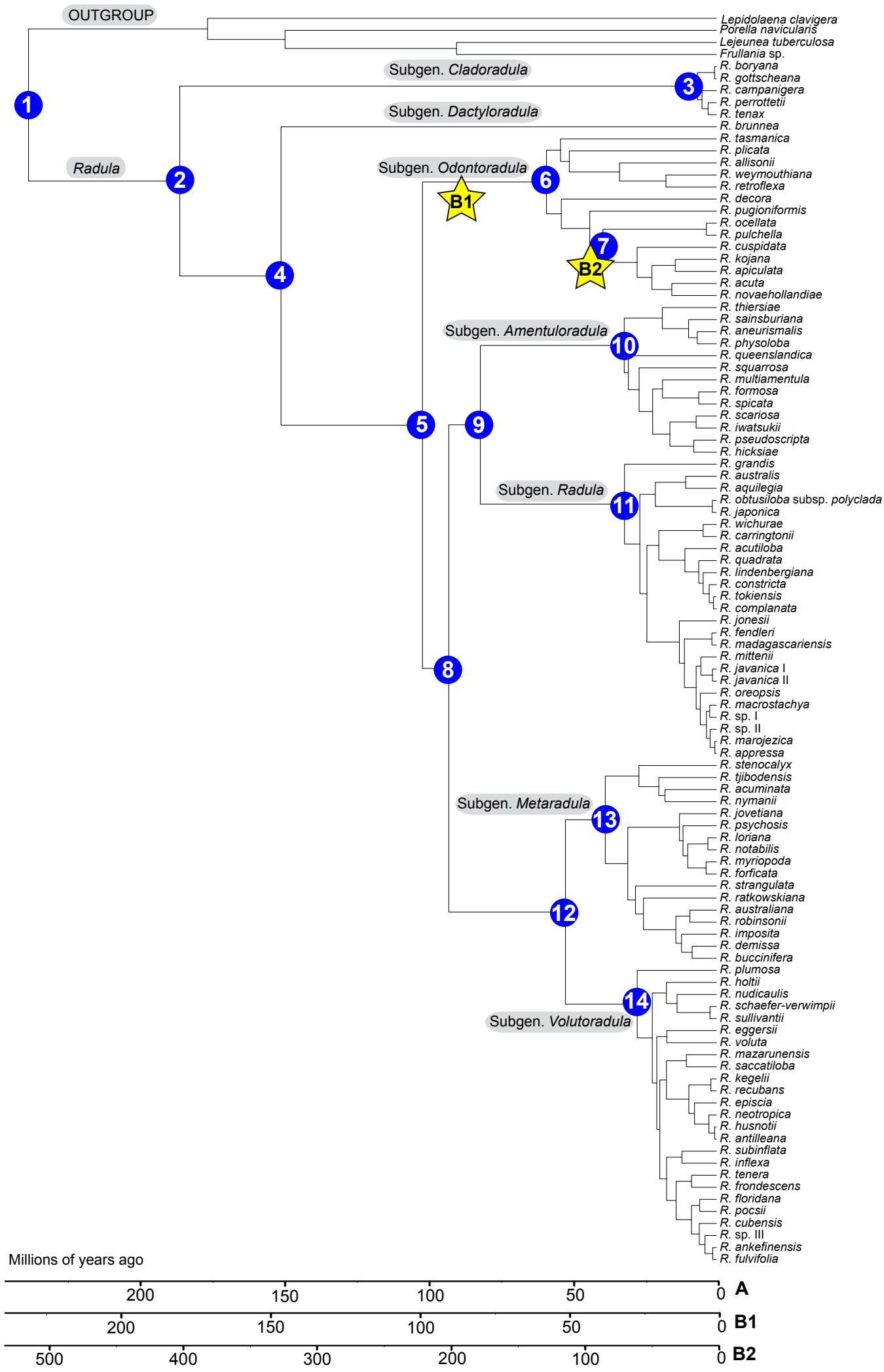

Figure 3. Phylogenetic chronogram for Radula with timescales resulting from different calibration approaches using BEAST. Scale bar A results from the divergence time estimation using a plastid standard substitution rate. Scale bar B1 results from an assignment of the fossil to the stem of subgenus Odontoradula whereas scale bar B2 results from a fossil assignment to the crown group of this subgenus. Stars indicate alternative fossil assignments. 
Table 3. Divergence time estimates for nodes of interest (see Fig. 3) in millions of years (Ma) before present with corresponding $95 \%$ highest posterior density (HPD) intervals in square brackets shown for three different dating approaches. Approach A, calibration with the chloroplast standard substitution rate; approach B1, assignment of the Radula fossil to the stem of subgenus Odontoradula; approach B2, crown group assignment of the Radula fossil to the stem of a clade within subgenus Odontoradula. See material and methods for details.

\begin{tabular}{lrrr}
\hline & Approach A & Approach B1 & Approach B2 \\
\hline Node & Node age [95\% HPD] & Node age [95\% HPD] & Node age [95\% HPD] \\
\hline 1 & $235.6[142.9-368.5]$ & $227.8[165.7-306.7]$ & $508.1[340.7-713.8]$ \\
2 & $183.8[109.9-289.1]$ & $176.3[135.1-227.4]$ & $392.2[266.5-551.5]$ \\
3 & $6.5[2.7-12.3]$ & $6.3[2.9-11.1]$ & $14.0[6.4-24.6]$ \\
4 & $149.1[91.6-236.6]$ & $142.7[116.9-179.8]$ & $319.3[221.4-444.5]$ \\
5 & $100.7[62.1-155.1]$ & $98.1[95.5-101.0]$ & $216.6[156.5-285.8]$ \\
6 & $58.2[35.8-90.8]$ & $57.4[43.0-72.9]$ & $126.1[105.4-159.5]$ \\
7 & $38.9[22.7-62.6]$ & $38.2[25.7-51.0]$ & $88.9[74.9-97.6]$ \\
8 & $91.7[56.6-142.3]$ & $90.1[79.0-97.3]$ & $197.2[143.9-265.9]$ \\
9 & $80.9[47.5-126.7]$ & $79.7[62.1-93.4]$ & $174.1[121.2-239.2]$ \\
10 & $31.6[19.2-50.2]$ & $31.0[21.6-42.0]$ & $68.5[44.7-95.2]$ \\
11 & $31.5[18.6-50.6]$ & $30.7[20.3-43.3]$ & $67.9[42.7-97.0]$ \\
12 & $51.7[32.0-81.3]$ & $51.1[37.7-65.2]$ & $111.8[75.8-153.2]$ \\
13 & $38.1[22.7-58.9]$ & $37.4[27.4-49.3]$ & $82.4[54.0-111.6]$ \\
14 & $27.1[16.0-42.9]$ & $26.7[18.5-36.4]$ & $58.1[38.1-82.9]$ \\
\hline
\end{tabular}

at the base of one of the bracts in the uppermost pair, again fertile. Gynoecial disc bearing around five archegonia $100-110 \mu \mathrm{m}$ long. Perianths not seen. Male reproductive structures not seen.

\section{Discussion}

The majority of extant and fossil Radula species have rounded rather than acute leaf lobes and one rather than two female bract pairs (Castle, 1936). On the basis of the acute leaf lobe apex, the female bracts in two pairs, and the production of gemmae, the fossil plant would be assigned to Radula subg. Odontoradula and placed into Yamada's (1979) Asian sect. Acutifoliae series Acutifoliae, were it extant. Ancestral state reconstructions support this placement (Fig. 2). However, extending this confidence to time calibrating the phylogeny by enforcing a minimum age of 98 million years on the node corresponding with series Acutifoliae results in divergence time estimates that are unrealistic (Fig. 3) as they even exceed most age estimates of the land plant crown group (Clarke et al., 2011; Fiz-Palacios et al., 2011; Magallón et al., 2013). Possibly, strongly deviating substitution rates within the main clades of Radula and related epiphyte lineages of liverworts account for the apparent young age of ser. Acutifoliae. We have no biological explanation for this scenario and were also not able to observe the deviant branch length of $R$. subg. Odontoradula species and related lineages in plastid DNA phylograms of Radula (e.g., Devos et al., 2011b). Accordingly, we consider a position of $R$. cretacea in the crown group of $R$. subg. Odontoradula as unlikely. Assignment of $R$. cretacea to the stem of $R$. subg. Odontoradula leads to divergence time estimates that are in good accordance with those based on standard substitution rates of seed-free land plants (Fig. 3; Patiño et al., 2017). They are also in good agreement with most other age estimates of Radula generated in dating analyses of major liverwort or land plant lineages (Heinrichs et al., 2007; Fiz-Palacios et al., 2011; Cooper et al., 2012; Feldberg et al., 2014; Laenen et al., 2014). These estimates were based on DNA sequence variation with integrated information from the fossil record. Some of these estimates seem to differ considerably; however, the large confidence intervals of the respective node age estimates broadly overlap and demonstrate the uncertainty in current age estimates of epiphyte lineages of liverworts (Supplement). We used similar datasets to Patiño et al. (2017); however, Patiño et al. (2017) applied a Yule prior. Our stepping stone analyses supported a birth-death rather than a Yule model to best fit our dataset. The corresponding analyses resulted in slightly older age estimates than those of Patiño et al. (2017) and our additional analyses with the Yule prior (Table 4). However, the older estimates obtained with the birth-death prior get support from the Radula fossil which indicates the presence of subg. Odontoradula already in the earliest late Cretaceous. Condamine et al. (2015) demonstrated the crucial importance of model choice in divergence time analyses and presented an example from cycads in which different priors resulted in strongly deviant divergence time estimates based on the same sequence dataset. Our choice of a birth-death model was supported not only by the stepping stone analyses but also seems reasonable when considering the Mesozoic or Paleozoic origin and the long stem lineages of Radula and its main crown group clades. These lineages, and indeed the fossil itself, both provide some evidence for extinction events in 
Table 4. Comparison of divergence time estimates resulting from BEAST analyses only differing in their tree prior. A plastid standard substitution rate was used to calibrate the dataset. In approach A, a birth-death tree prior was used, while in approach AY a purebirth (Yule) tree prior was implemented. Bayes factor values favor a birth-death tree prior (see Table 1). Node numbers correspond to Fig. 3. Node ages and their $95 \%$ highest posterior density (HPD) intervals are given in millions of years (Ma) before present.

\begin{tabular}{lrr}
\hline & Approach A & Approach AY \\
\hline Node & Node age [95\% HPD] & Node age [95\% HPD] \\
\hline 1 & $235.6[142.9-368.5]$ & $184.5[113.3-284.9]$ \\
2 & $183.8[109.9-289.1]$ & $154.1[96.3-241.6]$ \\
3 & $6.5[2.7-12.3]$ & $7.2[2.9-14.1]$ \\
4 & $149.1[91.6-236.6]$ & $127.7[78.6-198.6]$ \\
5 & $100.7[62.1-155.1]$ & $91.6[56.2-139.3]$ \\
6 & $58.2[35.8-90.8]$ & $56.2[35.4-87.6]$ \\
7 & $38.9[22.7-62.6]$ & $38.4[22.4-60.3]$ \\
8 & $91.7[56.6-142.3]$ & $84.1[51.6-128.3]$ \\
9 & $80.9[47.5-126.7]$ & $73.94[44.7-115.9]$ \\
10 & $31.6[19.2-50.2]$ & $33.4[19.9-52.6]$ \\
11 & $31.5[18.6-50.6]$ & $33.5[19.4-53-9]$ \\
12 & $51.7[32.0-81.3]$ & $51.9[31.9-81.0]$ \\
13 & $38.1[22.7-58.9]$ & $39.2[23.5-60.9]$ \\
14 & $27.1[16.0-42.9]$ & $29.2[17.1-45.7]$ \\
\hline
\end{tabular}

the early history of the genus that are not considered in a pure birth model.

Since a position of the fossil Radula cretacea in the crown group of subg. Odontoradula resulted in unrealistically old age estimates, we prefer to treat it as a stem group element of this subgenus. This hypothesis contradicts our ancestral character state reconstructions, which suggest that early Odontoradula taxa had rounded lobe apices, a single pair of female bracts, and no asexual reproduction by gemmae. However, the high amount of homoplasy within some character systems in extant Radula species (Renner, 2015) and implied rapid changes of character states within extant subgenera (Renner et al., 2013b) give reason to assume gains and losses of character states during earlier radiations on the Radula stem lineages. Such a scenario would explain that early stem group species of $R$. subg. Odontoradula share character states with derived crown group representatives in the $R$. pugioniformis $-R$. apiculata clade. It is possible that Radula lineages explore a certain morphospace and that a certain suite of character states can be repeatedly combined in new ways. Unfortunately, the poor Mesozoic fossil record of Radula disables a detailed reconstruction, yet Radula cretacea provides a note of caution for node calibrations using evidence from the fossil record (Parham et al., 2012). We thus propose balancing different lines of evidence, including information from standard substitution rates, results generated using secondary calibrations, and data based on the morphology of the fossil and related taxa (Lóriga et al., 2014;
Heinrichs et al., 2015; Schneider et al., 2015, 2016; Feldberg et al., 2017). The recently proposed fossilized birth-death approach was designed to overcome the problem of assigning fossils to certain nodes in divergence time analyses (Heath et al., 2014); however, this approach requires a dense fossil record and numerous morphological character states of both fossils and extant taxa to be coded (Arcila et al., 2015; Warnock et al., 2015). We were unable to successfully employ this approach because of the small number of Radula fossils, their incomplete preservation, and the monotonous morphology of both the majority of extant and fossil species (Grolle, 1987; Renner and Braggins, 2004; Renner, 2015; Heinrichs et al., 2016b; Kaasalainen et al., 2017).

Treating the Radula fossil as an early stem group element of $R$. subg. Odontoradula leads to results that are in good accordance with most other published divergence time estimates, especially with reconstructions based on published standard substitution rates of seed-free land plants. The corresponding phylogenetic chronograms provide evidence for a late Cretaceous origin of most subgenera of Radula and for an establishment of their crown groups in the Paleogene. This pattern possibly relates to changes in the terrestrial ecosystems during the Cretaceous Terrestrial Revolution (Meredith et al., 2011), especially the establishment of major angiosperm lineages in the Late Cretaceous (Wang et al., 2009; Couvreur et al., 2011; Coiffard et al., 2012), connected with a decline in gymnosperm diversity (Becker, 2000). The wide distribution of megathermal angiosperm forests in the early Cenozoic (Morley, 2011), their new canopy structure, and their more humid microclimate (Boyce et al., 2010) likely led to major changes in the main epiphyte lineages of liverworts and the establishment of their modern crown groups. This process was likely initiated in the Late Cretaceous, when angiosperms started to dominate many terrestrial ecosystems. The impact of the Cretaceous-Paleogene mass extinction on plant evolution is still incompletely understood (Vajda and Bercovici, 2014); however, the long stem lineages of the Radula subgenera may to some extent relate to these extinction processes. Similar topologies suggestive of the same pattern have been reconstructed in other Porellales genera such as Leptolejeunea (Spruce) Steph. (Bechteler et al., 2017), Lejeunea Lib. and Microlejeunea (Spruce) Steph. (Heinrichs et al., 2016a), and Frullania (Silva et al., 2016).

The way Radula cretacea has been preserved provides minimal insight into what microhabitat the plant occupied in life; however, its inclusion in amber is consistent with the hypothesis that a bark epiphyte or a trunk-base dweller is at hand. Burmese amber was produced by gymnosperm trees in a tropical environment (Grimaldi et al., 2002) and, although angiosperms occurred in this amber forest (Santiago-Blay et al., 2005; Chambers et al., 2010), it was likely dominated by gymnosperms. The modern morphology of the fossil leads to the question of if a switch from gymnosperm to angiosperm carrier trees required major morphological changes in plant bodies. The switch to angiosperm phorophytes likely 
involved an adaptation to a more humid microclimate and to a different light regime and possibly also to a somewhat deviant nutrient availability (Schneider et al., 2004). It does, however, not necessarily require changes of the general plant body plan, especially if adaptations to epiphyte growth such as complicated bilobed leaves, solely lateral branching, and fascicled rhizoids (Heinrichs et al., 2005) were already present in the liverwort lineages growing on gymnosperm bark. It is thus not surprising that other Burmese amber fossils of liverworts also have the morphological characteristics of extant genera (Heinrichs et al., 2012, 2014).

\section{Conclusions}

The first Cretaceous fossil of the leafy liverwort genus Radula provides crucial insights into the early evolution of predominantly epiphytic lineages of leafy liverworts. Character state reconstructions and a series of divergence time estimates suggest that the fossil is an early stem lineage representative of Radula subg. Odontoradula. Its modern morphology illustrates that switches from gymnosperm to angiosperm phorophytes did not require changes in plant body plans of epiphytic liverworts and provides evidence for morphological homoplasy in time. Even conservative node assignments of the fossil support older rather than younger age estimates of the Radula crown group, involving an establishment of most extant subgenera by the end of the Cretaceous and diversification of their crown groups in the Cenozoic.

Data availability. All necessary data are available in the Supplement.

\section{The Supplement related to this article is available online at https://doi.org/10.5194/fr-20-201-2017-supplement.}

Competing interests. The authors declare that they have no conflict of interest.

Acknowledgements. Financial support from the German Research Foundation (grant HE 3584/6 to JH) is gratefully acknowledged. This research was also supported by the National Natural Science Foundation of China (41572010, 41622201), the Chinese Academy of Sciences (XDPB05), and the Youth Innovation Promotion Association of CAS (no. 2011224). Further support came from the Foundation and Friends of the Royal Botanic Gardens, Sydney (travel grant to MR).

Edited by: Florian Witzmann

Reviewed by: Anders Hagborg and Jeff Duckett

\section{References}

Akaike, H.: Information theory as an extension of the maximum likelihood principle, in: Second International Symposium on Information Theory, edited by: Petrov, B. N and Csâki, F., Akadémia Kiado, Budapest, Hungary, 267-281, 1973.

Arcila, D., Pyron, R. A., Tyler, J. C., Orti, G., and Betancur, R. R.: An evaluation of fossil tip-dating versus node-age calibrations in tetraodontiform fishes (Teleostei: Percomorphaceae), Mol. Phylogenet. Evol., 82, 131-145, 2015.

Baele, G., Lemey, P., Bedford, T., Rambaut, A., Suchard, M. A., and Alekseyenko, A. V.: Improving the accuracy of demographic and molecular clock model comparison while accommodating phylogenetic uncertainty, Mol. Biol. Evol., 29, 2157-2167, 2012.

Baele, G., Li, W. L. S., Drummond, A. J., Suchard, M. A., and Lemey, P.: Accurate model selection of relaxed molecular clocks in Bayesian phylogenetics, Mol. Biol. Evol., 30, 239-243, 2013.

Bechteler, J., Schäfer-Verwimp, A., Lee, G. E., Feldberg, K., PérezEscobar, O. A., Pócs, T., Peralta, D. F., Renner, M. A. M., and Heinrichs, J.: Geographical structure, narrow species ranges, and Cenozoic diversification in a pantropical clade of epiphyllous leafy liverworts, Ecol. Evol., 7, 638-653, 2017.

Becker, P.: Competition in the regeneration niche between conifers and angiosperms: Bond's slow seedling hypothesis, Funct. Ecol., 14, 401-412, 2000.

Boyce, C. K. and Lee, J. E.: An exceptional role for flowering plant physiology in the expansion of tropical rainforests and biodiversity, Proc. R. Soc. B, 277, 3437-3443, 2010.

Boyce, C. K. and Leslie, A. B.: The paleontological context of angiosperm vegetative evolution, Int. J. Plant Sci., 173, 561-568, 2012.

Boyce, C. K., Lee, J. E., Field, T. S., Brodribb, T. J., and Zwieniecki, M. A.: Angiosperms helped put the rain in the rainforests: the impact of plant physiological evolution on tropical biodiversity, Ann. Mo. Bot. Gard., 97, 527-540, 2010.

Castle, H.: A revision of the genus Radula. Introduction and part I. Subgenus Cladoradula, Ann. Bryol., 9, 13-56, 1936.

Chambers, K. L., Poinar, G., and Buckley, R.: Tropidogyne, a new genus of Early Cretaceous Eudicots (Angiospermae) from Burmese amber, Novon, 20, 23-29, 2010.

Clarke, J., Warnock, R. C. M., and Donoghue, P. C. J.: Establishing a time-scale for plant evolution, New Phytol., 192, 266-301, 2011.

Coiffard, C., Gomez, B., Daviero-Gomez, V., and Dilcher, D. L.: Rise to dominance of angiosperm pioneers in European Cretaceous environments, P. Natl. Acad. Sci. USA, 109, 20955-20959, 2012.

Condamine, F. L., Nagalingum, N. S., Marshal, C. R., and Morlon, H.: Origin and diversification of living cycads: a cautionary tale on the impact of the branching process prior in Bayesian molecular dating, BMC Evol. Biol., 15, 65, 2015.

Cooper, E. D., Henwood, M. J., and Brown, E. A.: Are the liverworts really that old? Cretaceous origins and Cenozoic diversifications in Lepidoziaceae reflect a recurrent theme in liverwort evolution, Biol. J. Linn. Soc., 107, 425-441, 2012.

Couvreur, T. L. P., Forest, F., and Baker, W. J.: Origin and global diversification patterns of tropical rain forests: inferences from a complete genus-level phylogeny of palms, BMC Biol., 9, 44, 2011. 
Cruickshank, R. D. and Ko, K.: Geology of an amber locality in the Hukawng valley, Northern Myanmar, J. Asian Earth Sci., 21, 441-445, 2003.

Darriba, D., Taboada, G. L., Doallo, R., and Posada D.: JModelTest 2: More models, new heuristics and parallel computing, Nature Meth., 9, 772, 2012.

Devos, N., Renner, M. A. M., Gradstein, S. R., Shaw, A. J., Laenen, B., and Vanderpoorten, A.: Evolution of sexual systems, dispersal strategies and habitat selection in the liverwort genus Radula, New Phytol., 192, 225-236, 2011a.

Devos, N., Renner, M. A. M., Gradstein, S. R., Shaw, J., and Vanderpoorten, A.: Molecular data challenge traditional subgeneric divisions in the leafy liverwort Radula, Taxon, 60, 1623-1632, 2011 b.

Drummond, A. J., Suchard, M. A., Xie, D., and Rambaut, A.: Bayesian phylogenetics with BEAUti and the BEAST 1.7, Mol. Biol. Evol., 29, 1969-1973, 2012.

Feldberg, K., Schneider, H., Stadler, T., Schäfer-Verwimp, A., Schmidt, A. R., and Heinrichs, J.: Epiphytic leafy liverworts diversified in angiosperm-dominated forests, Sci. Rep., 4, 5974, 2014.

Feldberg, K., Vána, J., Schäfer-Verwimp, A., Krings, M., Gröhn, C., Schmidt, A. R., and Heinrichs, J.: Problems related to the taxonomic placement of incompletely preserved amber fossils: transfer of the Paleogene liverwort Cylindrocolea dimorpha (Cephaloziellaceae) to the extant Odontoschisma sect. Iwatsukia (Cephaloziaceae), Foss. Rec., 20, 147-157, https://doi.org/10.5194/fr-20-147-2017, 2017.

Fiz-Palacios, O., Schneider, H., Heinrichs, J., and Savolainen, V.: Diversification of land plants. Insights from a family-level phylogenetic analysis, BMC Evol. Biol., 11, 341, 2011.

Fletcher, B. J., Brentnall, S. J., Anderson, C. W., Berner, R. A., and Beerling, D. J.: Atmospheric carbon dioxide linked with Mesozoic and early Cenozoic climate change, Nature Geosci., 1, 4348, 2008.

Grimaldi, D. A., Engel, M. S., and Nascimbene, P. C.: Fossiliferous Cretaceous amber from Myanmar (Burma): its rediscovery, biotic diversity, and paleontological significance, Amer. Mus. Novit., 3361, 1-71, 2002.

Grolle, R.: Radula steerei sp. nov. - A further hepatic in Dominican Amber, Mem. New York Bot. Gard., 45, 259-263, 1987.

Heath, T. A., Huelsenbeck, J., and Stadler, T.: The fossilized birthdeath process for coherent calibration of divergence time estimates, P. Natl. Acad. Sci. USA, 111, E2957-E2966, 2014.

Heinrichs, J., Gradstein, S. R., and Wilson, H.: Towards a natural classification of liverworts (Marchantiophyta) based on the chloroplast gene $r b c \mathrm{~L}$, Cryptogam. Bryol., 26, 131-150, 2005.

Heinrichs, J., Hentschel, J., Wilson, R., Feldberg, K., and Schneider, H.: Evolution of leafy liverworts (Jungermanniidae, Marchantiophyta): estimating divergence times from chloroplast DNA sequences using penalized likelihood with integrated fossil evidence, Taxon, 56, 31-44, 2007.

Heinrichs, J., Reiner-Drehwald, M. E., Feldberg, K., Grimaldi, D. A., Nascimbene, P. C., von Konrat, M., and Schmidt, A. R.: Kaolakia borealis nov. gen. et sp. (Porellales, Jungermanniopsida), a leafy liverwort from the Cretaceous of Alaska, Rev. Palaeobot. Palyno., 165, 235-240, 2011.

Heinrichs, J., Reiner-Drehwald, M. E., Feldberg, K., von Konrat, M., Hentschel, J., Váňa, J., Grimaldi, D. A., Nascimbene, P.
C., and Schmidt, A. R.: The leafy liverwort Frullania (Jungermanniopsida) in the Cretaceous amber forest of Myanmar, Rev. Palaeobot. Palyno., 169, 21-28, 2012.

Heinrichs, J., Schäfer-Verwimp, A., Feldberg, K., and Schmidt, A. R.: The extant liverwort Gackstroemia (Lepidolaenaceae, Porellales) in Cretaceous amber from Myanmar, Rev. Palaeobot. Palyno., 203, 48-52, 2014.

Heinrichs, J., Scheben, A., Lee, G. E., Váňa, J., Schäfer-Verwimp, A., Krings, M., and Schmidt, A.: Molecular and morphological evidence challenges the records of the extant liverwort Ptilidium pulcherrimum in Eocene Baltic amber, PLoS ONE, 10, e0140977, https://doi.org/10.1371/journal.pone.0140977, 2015.

Heinrichs, J., Scheben, A., Bechteler, J., Lee, G. E., SchäferVerwimp, A., Hedenäs, L., Singh, H., Pócs, T., Nascimbene, P. C., Peralta, D. F., Renner, M., and Schmidt, A. R.: Crown group Lejeuneaceae and pleurocarpous mosses in early Eocene (Ypresian) Indian Amber, PloS ONE, 11, e0156301, https://doi.org/10.1371/journal.pone.0156301s, 2016a.

Heinrichs, J., Schmidt, A. R., Schäfer-Verwimp, A., Bauerschmidt, L., Neumann, C., Gröhn, C., Krings, M., and Renner, M. A. M. Revision of the leafy liverwort genus Radula in Baltic and Bitterfeld amber, Rev. Palaeobot. Palyno., 235, 157-164, 2016b.

Hennequin, S., Schuettpelz, E., Pryer, K. M., Ebihara, A., and Dubuisson, J.-Y.: Divergence times and the evolution of epiphytism in filmy ferns (Hymenophyllaceae) revisited, Int. J. Plant Sci., 169, 1278-1287, 2008.

Kaasalainen, U., Heinrichs, J., Renner, M. A. M., Hedenäs, L., Schäfer-Verwimp, A., Lee, G. E., Ignatov, M. S., Rikkinen, J., and Schmidt, A. R.: A Caribbean epiphyte community preserved in Miocene Dominican amber, Earth Environm. Sci. Trans. R. Soc. Edinb., in press, 2017.

Kania, I., Wang, B., and Szwedo, J.: Dicranoptycha Osten Sacken, 1860 (Diptera, Limoniidae) from the earliest Upper Cretaceous Burmese amber, Cretaceous Res., 52, 522-530, 2015.

Kass, R. E. and Raftery, A. E.: Bayes factor, J. Am. Stat. Assoc., 90, 773-795, 1995.

Kearse, M., Moir, R., Wilson, A., Stones-Havas, S., Cheung, M., Sturrock, S., Buyton, S., Cooper, A., Markowitz, S., Duran, C., Thierer, T., Ashton, B., Meintjes, P., and Drummond, A.: Geneious Basic: an integrated and extendable desktop software platform for the organization and analysis of sequence data, Bioinformatics, 28, 1647-1649, 2012.

Laenen, B., Shaw, B., Schneider, H., Goffinet, B., Paradis, E., Désamoré, A., Heinrichs, J., Villarreal, J. C., Gradstein, S. R., McDaniel, S. F., Long, D. G., Forrest, L. L., Hollingsworth, M. L., Crandall-Stotler, B., Davis, E. C., Engel, J., Von Konrat, M., Cooper, E. D., Patiño, J., Vanderpoorten, A., and Shaw, A. J.: Extant diversity of bryophytes emerged from successive post-Mesozoic diversification bursts, Nature Com., 5, 6134, https://doi.org/10.1038/ncomms6134, 2014.

Li, R., Sun, B., Wang, H., He, Y., Yang, G., Yan, D., and Lin, Z.: Marchantites huolinhensis sp. nov. (Marchantiales) - A new fossil liverwort with gemmae cups from the Lower Cretaceous of Inner Mongolia, China, Cretaceous Res., 50, 16-26, 2014.

Li, R., Wang, X., Jin, P., Ma, F., Yan, D., Lin, Z., and Sun, B.: Fossil liverworts from the Lower Cretaceous Huolinhe formation in Inner Mongolia, China, Acta Geol. Sin., 90, 838-846, 2016.

Lóriga, J., Schmidt, A. R., Moran, R. C., Feldberg, K., Schneider, H., and Heinrichs, J.: The first fossil of a bolbitidoid fern 
belongs to the early-divergent lineages of Elaphoglossum (Dryopteridaceae), Am. J. Bot., 101, 1466-1475, 2014.

Magallón, S., Hilu, K., and Quandt, D.: Land plant evolutionary timeline: gene effects are secondary to fossil constraints in relaxed clock estimation of age and substitution rates, Am. J. Bot., 100, 556-573, 2013.

Meredith, R. W., Janecka, J. E., Gatesy, J., Ryder, O. A., Fisher, C. A., Teeling, E. C., Goodbla, A., Eizirik, E., Simão, T. L. L., Stadler, T., Rabosky, D. L., Honeycutt, R. L., Flynn, J. J., Ingram, C. M., Steiner, C., Williams, T. L., Robinson, T. J., Burk-Herrick, A., Westerman, M., Ayoub, N. A., Springer, M. S., and Murphy, W. J.: Impacts of the Cretaceous Terrestrial Revolution and KPg extinction on mammal diversification, Science, 334, 521-524, 2011.

Morley, R. J.: Cretaceous and Tertiary climate change and the past distribution of megathermal rainforests, in: Tropical Rainforest Responses to Climatic Change, edited by: Bush, M. B., Flenley, J. R., and Gosling, W. D., Springer, Berlin, Heidelberg, Germany, 1-34, 2011.

Newton, A. E., Wikström, N., Bell, N., Forrest, L. L., and Ignatov, M. S.: Dating the diversification of the pleurocarpous mosses, in: Pleurocarpous mosses: Systematics and evolution, Systematics Association Special Volume 71, edited by: Newton, A. E. and Tangney, R., Taylor \& Francis/CRC Press, Boca Raton, 337-366, 2007.

Palmer, J. D.: Plastid chromosome, structure and evolution, in: The Molecular Biology of Plastids, edited by: Bogorad, L. and Vasil, I. K., Academic Press, San Diego, California, USA, 5-53, 1991.

Paradis, E., Claude, J., and Strimmer, K.: APE: Analyses of phylogenetics and evolution in R language, Bioinformatics, 20, 289290, 2004.

Parham, J. F., Donoghue, P. C, Bell, C. J., Calway, T. D., Head, J. J., Holroyd, P. A., Inoue, J. G., Irmis, R. B., Joyce, W. G., Ksepka, D. T., Patané, J. S. L., Smith, N. D., Tarver, J. E., van Tuinen, M., Yang, Z., Angielczyk, K. D., Greenwood, J. M., Hipsley, C. A., Jacobs, L., Makovicky, P. J., Müller, J., Smith, K. T., Theodor, J. M., Warnock, R. C. M., and Benton, M. J.: Best practices for justifying fossil calibrations, Syst. Biol., 61, 346-359, 2012.

Patiño, J., Devos, N., Vanderpoorten, A., Schäfer-Verwimp, A., and Renner, M. A. M.: The identity of Radula carringtonii Jack, J. Bryol., 35, 314-316, 2013.

Patiño, J., Wang, J., Renner, M. A. M., Gradstein, S. R., Laenen, B., Devos, N., Shaw, A. J., and Vanderpoorten, A.: Range size heritability and diversification patterns in the liverwort Radula, Mol. Phylogenet. Evol., 106, 73-85, 2017.

Rambaut, A., Suchard, M. A., Xie, D., and Drummond, A. J.: Tracer v1.6, available at: http://beast.bio.ed.ac.uk/Tracer (last access: 13 January 2017), 2014.

R Core Team: R: A language and environment for statistical computing. R Foundation for Statistical Computing, Vienna, Austria, available at: http://www.r-project.org (last access: 13 January 2017), 2016.

Renner, M. A. M.: Radula subg. Radula in Australasia and the Pacific (Jungermanniopsida), Telopea, 17, 107-167, 2014.

Renner, M. A. M.: Lobule shape evolution in Radula (Jungermanniopsida): one rate fits all?, Bot. J. Linn. Soc., 178, 222-242, 2015.
Renner, M. A. M. and Braggins, J. E.: The sterile gametophyte as a source of informative characters in the genus Radula (Radulaceae: Hepaticae), Nova Hedwigia, 78, 243-268, 2004.

Renner, M. A. M., Devos, N., Brown, E. A., and von Konrat, M.: New records, replacements, reinstatements and four new species in the Radula parvitexta and $R$. ventricosa species groups (Jungermanniopsida) in Australia: cases of mistaken identity, Aust. Syst. Bot., 26, 298-345, 2013a.

Renner, M. A. M., Devos, N., Brown, E. A., and von Konrat, M.: Three modes of heterochrony explain lobule diversity in Radula subgenus Cladoradula (Porellales, Jungermanniopsida), a small lineage of early land plants, Bot. J. Linn. Soc., 173, 153-175, 2013b.

Renner, M. A. M., Devos, N., Patiño, J., Brown, E. A., Orme, A., Elgey, M., Wilson, T. C., Gray, L. J., and von Konrat, M. J.: Integrative taxonomy resolves the cryptic and pseudo-cryptic Radula buccinifera complex (Porellales, Jungermanniopsida), including two reinstated and five new species, Phytokeys, 27, 1-113, 2013c.

Renner, M. A. M., Devos, N., Brown, E. A., and von Konrat, M.: A revision of Australian species of Radula subg. Odontoradula, Aust. Syst. Bot., 26, 408-447, 2014.

Santiago-Blay, J. A., Anderson, S. R., and Buckley, R. T.: Possible implications of two new angiosperm flowers from Burmese amber (Lower Cretaceous) for well-established-and diversified insect-plant associations, Entomol. News, 116, 341-346, 2005.

Schneider, H., Schuettpelz, E., Pryer, K. M., Cranfill, R., Magallón, S., and Lupia, R.: Ferns diversified in the shadow of angiosperms, Nature, 428, 553-557, 2004.

Schneider, H., Schmidt, A. R., Nascimbene, P. C., and Heinrichs, J.: A new Dominican amber fossil of the derived genus Pleopeltis confirms generic stasis in the epiphytic fern diversity of the West Indies, Organisms Diversity Evol., 15, 277-283, 2015.

Schneider, H., Schmidt, A. R., and Heinrichs, J.: Burmese amber fossils bridge the gap in the Cretaceous record of polypod ferns, Perspect. Pl. Ecol. Evol. Syst., 18, 70-78, 2016.

Schuettpelz, E. and Pryer, K. M.: Reconciling extreme branch length differences: decoupling time and rate through the evolutionary history of filmy ferns, Syst. Biol., 55, 485-502, 2006.

Schuster, R. M. and Janssens, J. A.: On Diettertia, an isolated Mesozoic member of the Jungermanniales, Rev. Palaeobot. Palyno., 57, 277-287, 1989.

Shi, G. H., Grimaldi, D. A., Harlow, G. E., Wang, J., Wang, J., Yang, M., Lei, W., Li, Q., and Li, X.: Age constraint on Burmese amber based on U-Pb dating of zircons, Cretaceous Res., 37, 155-163, 2012.

Silva, S. E., Silva, D. N., Almeida, T., Garcia, C. A., Paulo, O. A., and Sim-Sim, M.: Age estimates of Frullania (Frullaniaceae, Porellales) main lineages: another example of rapid and recent diversification in liverwort evolution, Syst. Biodivers., 15, 156$165,2016$.

Söderström, L., Hagborg, A., Von Konrat, M., Bartolomew-Began, S., Bell, D., Briscoe, L., Brown, E., Cargill, D. C., Cooper, E. D., Costa, D. P., Crandall-Stotler, B. J., Cooper, E. D., Dauphin, G., Engel, J., Feldberg, K., Glenny, D., Gradstein, S. R., He, X., Heinrichs, J., Hentschel, J., Ilkiu-Borges, A. L., Katagiri, T., Konstantinova, N. A., Larraín, J., Long, D., Nebel, M., Pócs, T., Puche, F., Reiner-Drehwald, E., Renner, M. A. M., SassGyarmati, A., Schäfer-Verwimp, A., Segarra-Moragues, J. G., 
Stotler, R. E., Sukkharak, P., Thiers, B., Uribe, J., Váňa, J., Villarreal, J., Wigginton, M., Zhang, L., and Zhu, R.-L.: World checklist of hornworts and liverworts, PhytoKeys, 59, 1-828, 2016.

Stadler, T.: On incomplete sampling under birth-death models and connections to the sampling-based coalescent, J. Theor. Biol., 261, 58-66, 2009.

Taylor, T. N., Taylor, E. L., and Krings, M.: Paleobotany. The Biology and Evolution of Fossil Plants, 2nd edition, Elsevier/Academic Press Inc, Burlington MA, London, San Diego, New York, 2009.

Tomescu, A. M. F.: The Early Cretaceous Apple Bay flora of Vancouver Island: a hotspot of fossil bryophyte diversity, Botany, 94, 683-695, 2016.

Vajda, V. and Bercovici, A.: The global vegetation pattern across the Cretaceous-Paleogene mass extinction interval: A template for other extinction events, Global Planet. Change, 122, 29-49, 2014.

Villarreal, J. C. and Renner, S. S.: A review of molecular-clock calibrations and substitution rates in liverworts, mosses, and hornworts, and a timeframe for a taxonomically cleaned-up genus Nothoceros, Mol. Phylogenet. Evol., 78, 25-35, 2014.

Villarreal, J. C., Crandall-Stotler, B. J., Hart, M. J., Long, D. G., and Forrest, L. L.: Divergence times and the evolution of morphological complexity in an early land plant lineage (Marchantiopsida) with a slow molecular rate, New Phytol., 209, 1734-1746, 2016.
Wang, H., Moore, M. J., Soltis, P. S., Bell, C. D., Brockington, S. F., Alexandre, R., Davis, C. C., Latvis, M., Manchester, S. R., and Soltis, D. E.: Rosid radiation and the rapid rise of angiospermdominated forests, P. Natl. Acad. Sci. USA, 106, 3853-3858, 2009.

Warnock, R. C. M., Parham, J. F., Joyce, W. G., Lyson, T. R., and Donoghue, P. C. J.: Calibration uncertainty in molecular dating analyses: there is no substitute for the prior evaluation of time priors, Proc. Roy. Soc. B, 282, 20141013, https://doi.org/10.1098/rspb.2014.1013, 2015.

Xie, W., Lewis, P. O., Fan, Y., Kuo, L., and Chen, M.-H.: Improving marginal likelihood estimation for Bayesian phylogenetic model selection, Syst. Biol., 60, 150-160, 2011.

Yamada, K.: A revision of Asian taxa of Radula, Hepaticae, J. Hattori Bot. Lab., 45, 201-322, 1979.

Yamada, K.: An alphabetical list of the species and infracpecific taxa of the genus Radula (Radulaceae), J. Hattori Bot. Lab., 60 , 175-186, 1986.

Zwieniecki, M. A. and Boyce, C. K.: Evolution of a unique anatomical precision in angiosperm leaf venation lifts constraints on vascular plant ecology, Proc. Roy. Soc. B, 281, 2013289 , https://doi.org/10.1098/rspb.2013.2829, 2014. 